\title{
High stromal and epithelial human GH gene expression is associated with proliferative disorders of the mammary gland
}

\author{
M Raccurt, P E Lobie ${ }^{1}$, E Moudilou, T Garcia-Caballero ${ }^{2}$, \\ L Frappart ${ }^{3}$, G Morel and H C Mertani \\ CNRS UMR 5123, Claude Bernard Lyon-I University, Villeurbanne, France \\ ${ }^{1}$ Institute of Molecular and Cell Biology, National University of Singapore, Republic of Singapore \\ ${ }^{2}$ Department of Morphological Sciences, University of Santiago, Santiago de Compostela, Spain \\ ${ }^{3}$ Department of Anatomy and Pathology, Edouard Herriot Hospital, Lyon, France \\ (Requests for offprints should be addressed to G Morel, CNRS UMR 5123, Bât. 404/R. Dubois, 3ème étage, Université Claude Bernard-Lyon I, \\ 43 Boulevard du 11 Novembre 1918, F-69622 Villeurbanne Cedex, France; Email: gerard.morel@univ-lyon1.fr)
}

\begin{abstract}
We have demonstrated and localized human GH (hGH) gene expression in surgical specimens of normal human mammary gland and in proliferative disorders of the mammary gland of increasing severity using sensitive in situ RT-PCR methodology. hGH mRNA identical to pituitary hGH mRNA was first detected by RT-PCR of RNA derived from samples of normal human mammary gland. Cellular localization of hGH gene expression in the normal mammary gland exhibited restriction to luminal epithelial and myoepithelial cells of the ducts and to scattered stromal fibroblasts. We subsequently examined the expression of the hGH gene in three progressive proliferative disorders of the human mammary gland, i.e. a benign lesion (fibroadenoma), a pre-invasive stage (intraductal carcinoma) and an invasive ductal carcinoma. hGH mRNA was readily detected in the tumoral and nontumoral epithelial components and also in cells of the reactive stroma including fibroblasts, myofibroblastic and myoepithelial cells, inflammatory infiltrate lymphocytes and endothelial cells in areas of neovascularization. In all
\end{abstract}

three proliferative disorders examined, the intensity of the cellular labeling observed in both the epithelial and stromal compartments was always stronger compared with that in adjacent normal tissue. hGH protein was also present in significantly higher concentration in extracts derived from proliferative disorders of the mammary gland compared with extracts derived from normal mammary gland. We also examined $\mathrm{hGH}$ gene expression in axillary lymph nodes not containing and containing metastatic mammary carcinoma. hGH gene expression was evidenced in metastatic mammary carcinoma cells and in reactive stromal cells by both in situ hybridization and in situ RT-PCR. In contrast, in lymph nodes not containing metastatic mammary carcinoma, hGH mRNA was detected only by use of in situ RT-PCR. Thus, increased expression of the hGH gene in the epithelial component and the de novo stromal expression in proliferative disorders of the mammary gland are suggestive of a pivotal role for autocrine $\mathrm{hGH}$ in neoplastic progression of the mammary gland.

Journal of Endocrinology (2002) 175, 307-318

\section{Introduction}

The human growth hormone (hGH) receptor is expressed in the normal human mammary gland and in various benign and malignant human mammary gland disorders (Sobrier et al. 1993, Decouvelaere et al. 1995, Mertani et al. 1995, 1998, Gebre-Medhin et al. 2001). Cellular localization of the hGH receptor in the human mammary gland demonstrated that it is expressed by cells of the epithelial and stromal components and both are therefore responsive to hGH (Mertani et al. 1998, Gebre-Medhin et al. 2001). A number of studies have demonstrated an association between the somatotropic axis and the risk of developing carcinoma of the mammary gland (Emerman et al. 1985, Rose et al. 1988, Maddox et al. 1992, Peyrat et al. 1993, Hankinson et al. 1998, Toniolo et al. 2000) although these studies have focused on circulating hGH and/or human insulin-like growth factor-I (hIGF-I). hGH mRNA has also been detected by RT-PCR in RNA extracted from normal human mammary gland and in benign and malignant disorders of the human mammary gland (Mol et al. 1995a). This study did not delineate which cell type in the human mammary gland expressed the hGH gene even though the investigators did localize immunoreactive hGH to epithelial cells (Mol et al. 1995a). Thus, the precise cellular localization of hGH gene expression in the normal and neoplastic human mammary gland remains to be determined. 
We have recently generated a model system to study the cellular effects of autocrine hGH production in human mammary carcinoma cells in which the hGH gene or a translation-deficient hGH gene was stably transfected into MCF-7 cells (Kaulsay et al. 1999). Autocrine hGHproducing mammary carcinoma cells demonstrated marked IGF-I-independent proliferation in both serumfree and serum-containing conditions (Kaulsay et al. 1999). The increase in mammary carcinoma cell number as a consequence of autocrine production of $\mathrm{hGH}$ is a result of both increased mitogenesis and decreased apoptosis (Kaulsay et al. 1999, 2000). We have concomitantly identified the p38 MAP kinase-dependent transcription factor $\mathrm{CHOP}$ (C/EBP homologous protein) as one mediator of the protection from apoptosis afforded by autocrine hGH in mammary carcinoma cells (Mertani et al. 2001). Interestingly, autocrine production of hGH by mammary carcinoma cells specifically regulates gene expression in comparison with exogenous hGH. One such example is the inhibition of placental transforming growth factor- $\beta$ (PTGF- $\beta$ ) gene transcription by autocrine-produced but not exogenous hGH (Graichen et al. 2002). In addition, autocrine production of $\mathrm{hGH}$ resulted in enhancement of the rate of mammary carcinoma cell spreading on a collagen substrate, suggesting that autocrine hGH may influence mammary carcinoma cell migration and or/metastasis (Kaulsay et al. 2000, 2001). The effects of autocrine hGH on mammary carcinoma cell behavior are specifically mediated via the hGH receptor (Kaulsay et al. 2001). Thus, autocrine production of hGH by human mammary carcinoma cells may direct mammary carcinoma cell behavior to impact negatively on the clinical prognosis.

In this study, we have examined the cellular localization of hGH gene expression in the normal human mammary gland, in three proliferative disorders of the mammary gland of increasing severity (fibroadenoma, in situ carcinoma, invasive carcinoma) and also in metastatic axillary lymph node. We demonstrate that the hGH gene is primarily expressed in the epithelial and myoepithelial ductal cells of the normal human mammary gland. In a typical benign lesion (fibroadenoma) we demonstrate that the hGH gene is expressed in the proliferative epithelial cells and observe de novo stromal expression of the hGH gene. Further, with the use of well-characterized tumoral patterns from a pre-invasive to highly invasive phenotype we demonstrate that de novo stromal expression of the hGH gene is associated with the progression of mammary gland proliferative disorders. Finally, metastatic mammary carcinoma cells express significantly higher levels of hGH mRNA than normal mammary epithelial cells. This study, when combined with the reported hyperproliferative effect of autocrine hGH in mammary carcinoma cells, demonstrates the presence of an autocrine loop which would negatively affect neoplastic progression of the human mammary gland.

\section{Materials and Methods}

\section{Specimens}

Sixty-one cases of primary resections of carcinoma of the mammary gland were retrieved from the Anatomy and Pathology files of the Complejo Hospitalario Universitario de Santiago (Spain) and from the Pathology files of Lyon Edouard Herriot Hospital (France), according to the local Institutional Review Board requirements. The surgical specimens were selected as representative samples of three typical situations of progressive proliferative disorders of the human mammary gland according to their characteristic morphological growth patterns. The samples included normal breast $(n=4)$, fibroadenoma $(n=10)$ with typical benign epithelial and fibroblastic proliferation, in situ ductal carcinoma $(n=15)$ demonstrating the typical development of carcinomatous cells inside the ducts and a newly formed stroma surrounding these enlarged ducts. Nuclear grading was used to classify the samples of in situ ductal carcinoma from non-high-grade cribriform type to highgrade form with comedo-type necrosis. Samples of in situ ductal carcinoma had no development of lymph node metastasis and featured both the reactive stroma and the pre-existing connective tissue. Invasive ductal carcinomas $(n=21)$ were identified according to Scarff and Bloom grade (II and III) and lymph node status, and exhibited the typical feature of extensive proliferation of tumor cells within a loose neosynthesized stroma. Among these cases, three exhibited lymph node metastasis. Estrogen receptor $(\mathrm{ER})$ and progesterone receptor $(\mathrm{PR})$ status of the invasive ductal carcinoma samples was performed by immunocytochemistry and classified as $\mathrm{ER}+\mathrm{PR}+(n=8), \mathrm{ER}+$ $\mathrm{PR}-(n=6), \mathrm{ER}-\mathrm{PR}+(n=1)$ and $\mathrm{ER}-\mathrm{PR}-(n=6)$. We also selected axillary lymph nodes not containing $(n=5)$ and containing $(n=6)$ metastasized mammary carcinoma cells. We selected cases in which the metastases filled and extended into the subcapsular and radial sinuses of the lymph node before stromal invasion and that exhibited the architectural patterns of the primary carcinoma. Control normal tissue was obtained at a distance from tumors in cases of complete mastectomy. The surgical specimens were either fixed in $4 \%$ buffered formalin, dehydrated and embedded in paraffin for in situ hybridization (ISH) and in situ RT-PCR, or directly frozen in liquid nitrogen for RNA purification. Sections of human liver and human pituitary were used for control purposes.

\section{Oligonucleotide primers and probes}

Specific 20-mer oligonucleotide primers were synthesized (Eurobio, Les Ulis, France) and used after further HPLC purification. hGH sequences used as primers were directed toward selected regions of exons 3 and 5 of the hGH gene as previously described (Kaulsay et al. 
1999); sense: 5'-CCGACACCCTCCAACAGGGA3'; antisense: 5'-CCTTGTCCATGTCCTTCCTG-3'. Amplification yielded the predicted $342 \mathrm{bp}$ cDNA product. The product was digested with RsaI to verify its identity, resulting in $209 \mathrm{bp}$ and $133 \mathrm{bp}$ products.

Two 30-mer oligonucleotide probes directed towards selected regions of exons 4 and 5 were designed in order to be used for both ISH and in situ RT-PCR. The antisense probe was used for ISH of GH mRNA, and the sense probe used as ISH control. The sense and antisense probes mixed together were used with a prior target-denaturation step for hybridization of the in situ RT-PCR product; sense probe 5'-GCTGCTCCGCATCTCCCTGCTGC TCATCCA-3'; antisense probe $5^{\prime}$-GCGTCATCGTT GTGTGAGTTTGTGTCGAAC-3'. The probes were $3^{\prime}$ end-labeled with digoxigenin-11-dUTP (Roche Diagnostics, Meylan, France), verified and purified as previously described (Recher et al. 2001) prior to performing ISH or in situ RT-PCR.

\section{Liquid RT-PCR}

Total RNA extraction of liquid nitrogen-powdered tissues was performed using the RNeasy kit (Qiagen, Courtaboeuf, France) following the instructions of the manufacturer. RT-PCR was performed using the Onestep RT-PCR kit (Qiagen). The reaction was carried out in a $50 \mu \mathrm{l}$ volume containing $0.5 \mu \mathrm{g}$ total RNA, $1 \times$ Qiagen Onestep RT-PCR buffer, $400 \mu \mathrm{M}$ of each dNTP, $1 \times$ Q-solution, $0.6 \mu \mathrm{M}$ of each sense and antisense primers and $2 \mu \mathrm{l}$ Qiagen Onestep RT-PCR enzyme mix. Total RNA was reverse transcribed into cDNA for $30 \mathrm{~min}$ at $50{ }^{\circ} \mathrm{C}$, then Hot Start Taq DNA Polymerase was activated by heating for $15 \mathrm{~min}$ at $95^{\circ} \mathrm{C}$. The PCR was performed for 40 cycles according to the following program: initial denaturation at $94^{\circ} \mathrm{C}$ for $50 \mathrm{~s}$, annealing at $62{ }^{\circ} \mathrm{C}$ for $50 \mathrm{~s}$, elongation at $72{ }^{\circ} \mathrm{C}$ for $1 \mathrm{~min}$, final extension step at $72{ }^{\circ} \mathrm{C}$ for $10 \mathrm{~min}$. Five microliters of each PCR product were visualized by ethidium bromide staining on a $1.5 \%$ agarose gel. Validation of the liquid RT-PCR was performed on isolated RNA from human mammary carcinoma cells which had been stably transfected with the hGH gene (MCF-hGH) (Kaulsay et al. 1999).

\section{ISH}

ISH using digoxigenin-labeled probe was performed as described (Mertani et al. 1998). Briefly, deparaffinized and rehydrated $7 \mu \mathrm{m}$ sections were digested with $5 \mu \mathrm{g} / \mathrm{ml}$ proteinase $\mathrm{K}$ (Roche) at $37^{\circ} \mathrm{C}$ for $15 \mathrm{~min}$ in a Tris $(20 \mathrm{mM})-\mathrm{CaCl}_{2}(2 \mathrm{mM})$ buffer. Following dehydration, and air-drying, the sections were covered with $1 \mathrm{ml}$ hybridization mixture containing $50 \%$ deionized formamide, $10 \%$ dextran sulfate, $4 \times$ standard saline citrate $(1 \times$ SSC: $0 \cdot 15 \mathrm{M} \mathrm{NaCl}, 0 \cdot 015 \mathrm{M}$ sodium citrate, $\mathrm{pH} 7 \cdot 0$ ),
$1 \times$ Denhardt's solution, $500 \mu \mathrm{g} / \mathrm{ml}$ yeast tRNA, $500 \mu \mathrm{g} /$ $\mathrm{ml}$ salmon testes DNA and $30 \mathrm{pmol}$ labeled probe. Posthybridization washes were performed sequentially for $1 \mathrm{~h}$ in $2 \times \mathrm{SSC}$ and $30 \mathrm{~min}$ in $1 \times \mathrm{SSC}$ at room temperature. Immunodetection of the hybrids was performed with alkaline phosphatase-conjugated anti-digoxigenin (Roche) and using NBT-BCIP as chromogen (Roche). Validation of the ISH reaction was performed on human pituitary sections as positive control and human liver sections as negative control, and included several controls as described (Mertani et al. 1998). No counterstaining was performed.

\section{In situ RT-PCR}

In situ RT-PCR was performed on $7 \mu \mathrm{m}$ thick sections mounted on in situ RT-PCR glass slides (Applied Biosystem, Courtaboeuf, France) as described (Recher et al. 2001). Briefly, deparaffinized sections treated with proteinase K (Dako, Trappes, France) were dehydrated and air-dried. First, $100 \mu \mathrm{l}$ in situ RT reaction mixture containing $50 \mathrm{mM}$ Tris- $\mathrm{HCl} \mathrm{pH} 8 \cdot 3,75 \mathrm{mM} \mathrm{KCl}$, $10 \mathrm{mM}$ dithiothreitol, $75 \mathrm{mM} \mathrm{MgCl}_{2}, 1 \mathrm{mM}$ dNTP (Promega, Charbonnières, France), $1 \mu \mathrm{M}$ antisense primer, $100 \mathrm{U}$ RNase inhibitor (Promega), and $200 \mathrm{U}$ M-MLV reverse transcriptase (Life Technologies, Cergy Pontoise, France) were prepared. The sections were then covered with $45 \mu \mathrm{l}$ reaction mixture, sealed with amplicover discs and amplicover clips (Applied Biosystems), and incubated at $42{ }^{\circ} \mathrm{C}$ for $1 \mathrm{~h}$. Amplicover discs and clips were removed and sections were washed in $0.1 \mathrm{M}$ phosphate buffer for $5 \mathrm{~min}$ at room temperature, dehydrated and air-dried. Then, $100 \mu \mathrm{l}$ in situ PCR buffer containing $67 \mathrm{mM}$ Tris- $\mathrm{HCl}$ pH 8.8, $16 \mathrm{mM}\left(\mathrm{NH}_{4}\right)_{2} \mathrm{SO}_{4}, 0 \cdot 01 \%$ Tween 20, $3 \mathrm{mM} \quad \mathrm{MgCl}_{2}, \quad 0.5 \mathrm{mM}$ each dNTP (Promega), $1 \mu \mathrm{M}$ each primer and $20 \mathrm{U}$ Taq DNA polymerase (Eurobio) were prepared. The sections were covered with $45 \mu \mathrm{l}$ in situ PCR reaction mixture, sealed and placed on a GeneAmp in situ PCR system 1000 thermal cycler (Perkin-Elmer, Courtaboeuf, France). The Hot Start PCR method was used for 20 cycles according to the following program: denaturation at $94^{\circ} \mathrm{C}$ for $45 \mathrm{~s}$, annealing at $62{ }^{\circ} \mathrm{C}$ for $45 \mathrm{~s}$, extension at $72{ }^{\circ} \mathrm{C}$ for $1 \mathrm{~min}$, and final extension at $72{ }^{\circ} \mathrm{C}$ for $5 \mathrm{~min}$. Sections were then washed for $5 \mathrm{~min}$ in phosphate buffer, fixed $15 \mathrm{~min}$ in 4\% paraformaldehyde at room temperature, rinsed in $0 \cdot 1 \mathrm{M}$ phosphate buffer for $5 \mathrm{~min}$, dehydrated and air-dried. Sections were then processed for detection of PCRgenerated products as follow: denaturation for $3 \mathrm{~min}$ at $94^{\circ} \mathrm{C}$, quick chill on ice for $5 \mathrm{~min}$ and overnight hybridization at $40{ }^{\circ} \mathrm{C}$ with $20 \mathrm{pmol} / \mathrm{ml}$ sense- and antisenselabeled probes. Post-hybridization washes were performed sequentially for $1 \mathrm{~h}$ in $2 \times \mathrm{SSC}$ and $30 \mathrm{~min}$ in $1 \times \mathrm{SSC}$ at room temperature and hybrids were revealed as described in the ISH section. Validation of the in situ RT-PCR reaction was performed as described (Recher et al. 2001) on human pituitary sections as positive control and human 
liver sections as negative control, and included omission of the reverse transcriptase and omission of the Taq DNA polymerase as supplementary controls. No counterstaining was performed.

\section{ELISA analysis}

Total protein extraction of liquid nitrogen-powdered tissues was performed in lysis buffer: 1\% Triton X-100, $1 \mathrm{mM}$ EDTA, $1 \mathrm{mM}$ EGTA, $1 \mathrm{mM}$ phenylmethylsulfonyl fluoride, $0.5 \%$ Nonidet P-40, $50 \mathrm{mM}$ Tris $-\mathrm{HCl} \mathrm{pH}$ $7 \cdot 4$, and one complete mini-protease inhibitor cocktail (Roche). After $30 \mathrm{~min}$ on ice with agitation, the suspension was homogenized and cell debris removed. The supernatants were collected and protein concentration determined by the Bradford method. The hGH protein quantification in the specimens was performed using an hGH ELISA kit (Roche), performed according to the manufacturer's instructions. MCF-hGH cells were used as hGH protein-positive control as previously described (Kaulsay et al. 1999).

\section{Results}

\section{Expression of hGH mRNA in normal human mammary} gland

hGH gene expression has previously been detected in human mammary gland by RT-PCR (Mol et al. 1995a). However, the mammary gland is composed of heterogeneous cell types and the cell type(s) responsible for the production of hGH mRNA in the human mammary gland has not been identified. As a first step to determine the expression of hGH gene in the human mammary gland we isolated RNA from samples of normal human mammary gland and subjected them to RT-PCR analysis. For control purposes we also isolated RNA from human mammary carcinoma cells which had been stably transfected with the hGH gene (MCF-hGH) (Kaulsay et al. 1999). Reverse transcription followed by amplification with oligonucleotide primers specific for hGH mRNA of RNA extracted from normal human mammary gland produced a fragment of the expected size of $342 \mathrm{bp}$ (Fig. 1A). The identity of the PCR product was verified by RsaI restriction digestion to yield the appropriate size products of 209 and $133 \mathrm{bp}$ (Fig. 1A). Sequence analysis also showed the PCR product to be identical to the $342 \mathrm{bp} \mathrm{hGH-N}$ product (data not shown). To control for RNA quality we also amplified human $\beta$-actin mRNA by RT-PCR from RNA obtained from normal human mammary gland (Fig. 1A). The parental untransfected MCF-7 cells did not express the hGH gene as previously reported (Kaulsay et al. 1999) and were also used as a negative RT-PCR control.

In order to determine which cells from the normal human mammary gland expressed hGH mRNA, in situ
RT-PCR methodology was utilized. Initial attempts to localize hGH mRNA by direct ISH lacked the sensitivity required to obtain a signal significantly above background. We therefore resorted to the use of in situ RT-PCR methodology, which allows for the precise histological localization of low-level expressed mRNA within a heterogeneous tissue. We have previously developed, validated (Morel et al. 1998) and utilized this technique (Recher et al. 2001). The localization of hGH mRNA is indicated by a dark purple precipitate over the cell type (Figs 1, 2 and 3). In sections obtained from normal human mammary gland, the presence of hGH mRNA was detected in moderate amounts in both luminal epithelial and myoepithelial cells of the ducts (Fig. 1B). In the mammary gland stromal compartment, scattered fibroblasts were labeled but to a much lower extent compared with the labeling of the epithelial and myoepithelial cells (Fig. 1B). Endothelial cells of small arterioles were also labeled. No specific signal could be detected in the absence of the reverse transcriptase, demonstrating that the signal was not due to amplification of genomic DNA. In order to ensure the specificity of the in situ RT-PCR signal, we examined hGH gene expression in normal human liver. The presence of hGH mRNA could not be observed by direct ISH on sections of human liver. However, by the use of in situ RT-PCR, we observed that both endothelial and smooth muscle cells of the blood vessel wall of portal spaces expressed significant levels of hGH mRNA, whereas no signal was observed in the hepatocyte (Fig. 1C).

\section{Localization of $h \mathrm{GH}$ gene expression in proliferative disorders of the human mammary gland}

Total RNA from fibroadenoma, intraductal in situ carcinoma and invasive ductal carcinoma of the human mammary gland was isolated and demonstration of hGH gene expression was first performed by liquid RT-PCR. Use of the same oligonucleotide primers and RT-PCR conditions demonstrated the expected $342 \mathrm{bp}$ product in all specimens examined (Fig. 2A). The identity of the PCR product was verified by $\mathrm{RsaI}$ restriction digestion (Fig. $2 \mathrm{~A}$ ), and RNA quality was verified by RT-PCR of human $\beta$-actin mRNA from the same RNA samples used above (Fig. 2A). Thus proliferative disorders of the human mammary gland also express the hGH gene.

Cellular localization of hGH mRNA in the benign proliferative fibroadenoma was subsequently determined. An intense signal for hGH mRNA was observed in the proliferating epithelial cells of the ducts and in the cellular component of the neoformed fibrillar trabeculae of fibroproliferative foci (Fig. 2B). Careful examination of consecutive sections showed that labeling intensity of the epithelial and stromal cells of the pathological tissue was always greater than the surrounding normal tissue. Even though an intense signal for hGH mRNA was obtained by 
A
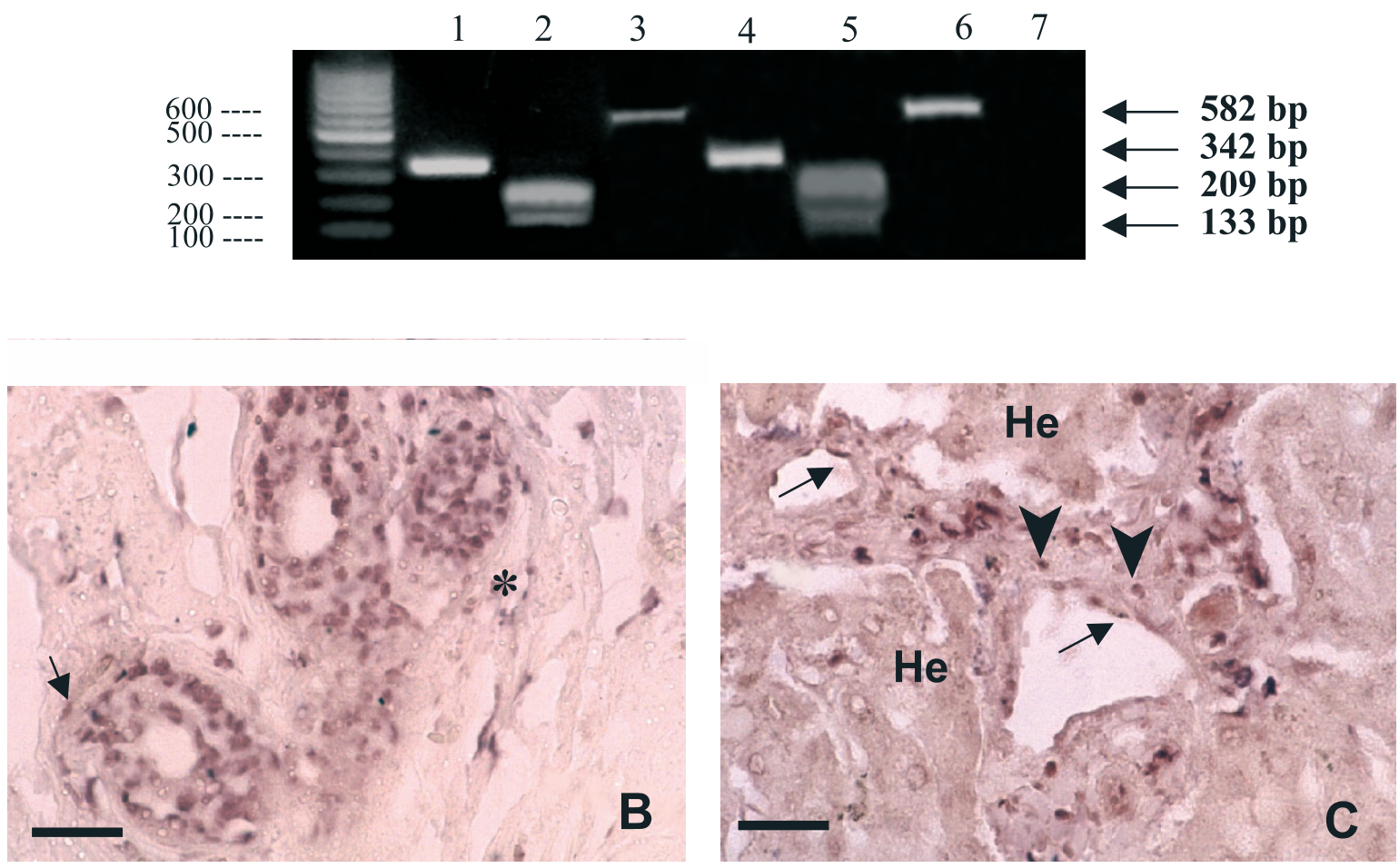

Figure 1 RT-PCR demonstration of hGH gene expression in normal human mammary gland. (A) Liquid RT-PCR produced a 342 bp product. The PCR product was digested with Rsal to yield two fragments of 209 and 133 bp. RT-PCR of $\beta$-actin mRNA was utilized for each sample to assess mRNA quality. The amplified fragments were visualized with ethidium bromide after agarose gel electrophoresis. Lane 1, amplified hGH fragment from MCF-7 cells stably transfected with the hGH gene (MCF-hGH); lane 2, Rsal digest of lane 1; lane 3, amplified $582 \mathrm{bp}$ of $\beta$-actin fragment from MCF-hGH; lane 4, amplified hGH fragment from normal human mammary gland; lane 5, Rsal digest of lane 4; lane 6 , amplified $\beta$-actin fragment from normal human mammary gland; lane 7, lack of amplified fragment from normal human mammary gland when Taq polymerase was omitted. Molecular mass markers are indicated on the left-hand side of the gel. (B) Cellular localization of hGH gene expression in the normal human mammary gland by in situ RT-PCR. The signal obtained after in situ RT-PCR of hGH appeared as a brown precipitate and was predominantly associated with the two-cell-layered epithelium and myoepithelial cells (arrow) of the ducts. A very faint in situ RT-PCR signal was detected in endothelial cells of a small artery (asterisk) occasionally in scattered fibroblasts within the dense fibrous stroma. (C) Cellular localization of hGH gene expression in normal human liver by in situ RT-PCR. A signal for hGH gene expression was restricted to the vessel wall of the portal space, within the endothelial cells (arrows) and smooth muscle cells (arrowheads), whereas hepatocytes (He) exhibited no signal. Bar is $100 \mu \mathrm{m}$.

in situ RT-PCR of the sections from fibroadenoma, we did not detect hGH mRNA in adjacent sections by direct ISH (Fig. 2C). Thus, in addition to the epithelial cell hGH mRNA expression observed in the normal human mammary gland, stromal fibroblasts of the fibroadenoma also gain the ability to express hGH mRNA. Therefore, increased hGH gene expression is associated not only with the proliferative epithelial cells, but also with the fibroproliferative foci of fibroadenoma.

We then proceeded to localize hGH mRNA in samples of intraductal carcinoma of the human mammary gland. hGH mRNA was readily localized by in situ RT-PCR to the carcinomatous cells present within the enlarged ducts of both non-high-grade cribriform type (Fig. 2D) and high-grade form (Fig. 2E). In addition, close examination of the sections demonstrated an intense signal for hGH gene expression in cells making up the reactive stroma surrounding the ducts enlarged by the carcinoma (Fig. $2 \mathrm{E})$. Concentric layers of myoepithelial and myofibroblastic cells of this newly formed stroma exhibited the strongest expression of hGH mRNA, in particular when the myoepithelial barrier was interrupted (Fig. 2E). Also, an intense signal for $\mathrm{hGH}$ gene expression was observed in lymphocytes invading the stroma (Fig. 2E). As a consequence of this increased hGH gene expression observed in the cells of the reactive stroma, we were able to detect a significant though faint signal when Taq DNA polymerase was omitted during the PCR reaction (Fig. 2F). This signal corresponded to hybridization to hGH cDNA obtained following the reverse transcription of mRNA and 

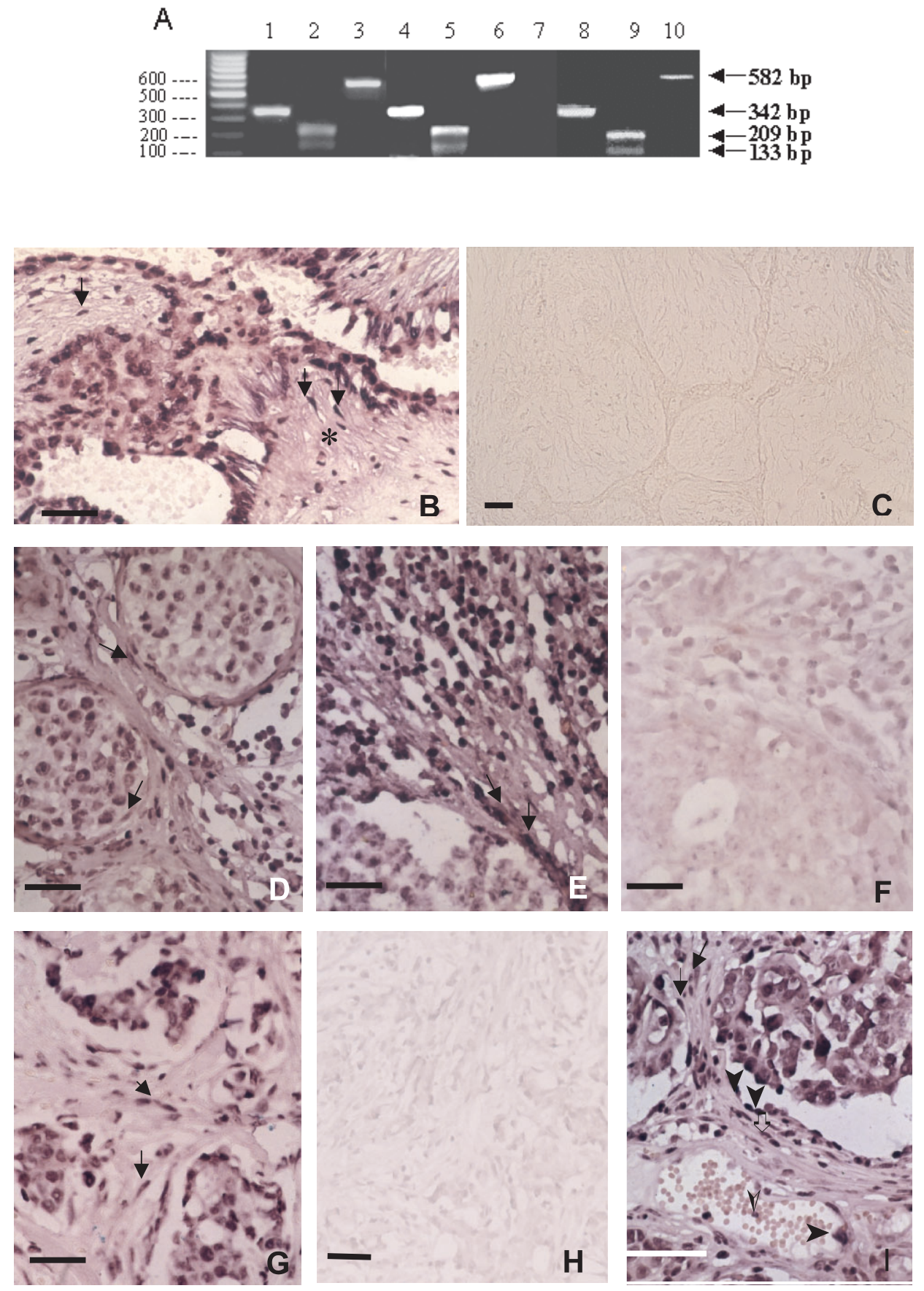
was in particular associated with the lymphocytes. hGH gene expression in human lymphocytes has previously been reported by other investigators (Hattori et al. 1990, Bates et al. 1997). Once more, the labeling intensity of the epithelial and stromal cells of the pathological tissue was always greater than the surrounding normal tissue.

On tissue sections obtained from patients with invasive ductal carcinoma of the mammary gland, expression of the hGH gene was evident in neoplastic cells organized in strands which extended into the surrounding loose stroma (Fig. 2G). The stroma exhibited numerous features of angiogenesis and all cells of the stroma expressed hGH mRNA as observed by the intense signal (Fig. 2G). No specific signal was detected in the absence of reverse transcription (Fig. 2H). Neoplastic epithelial cells heavily infiltrated the stromal compartment of this carcinoma, and the margin of advancing carcinoma was well delineated and featured important de novo vascularization. Within this area of stromal invasion, the neoplastic epithelial cells, fibroblasts and myofibroblasts all expressed significant levels of hGH mRNA. In addition, circulating lymphocytes and endothelial cells in areas of angiogenesis were also strongly labeled for hGH mRNA (Fig. 2I). No correlation was observed with the intensity of labeling for hGH mRNA and ER/PR status. Thus, during mammary carcinoma cell invasion prominent hGH gene expression is associated not only with neoplastic mammary carcinoma cells but also with cells directly involved in fibrogenesis and angiogenesis.

\section{$h \mathrm{GH}$ protein expression in normal and proliferative disorders of the mammary gland}

To determine if the increased levels of hGH mRNA observed in proliferative disorders of the mammary gland also resulted in increased hGH protein expression, we
Table $1 \mathrm{hGH}$ protein content (pg/mg of protein) from whole lysates of fresh frozen biopsies. Levels of hGH protein were determined by ELISA as described in Material and Methods. Results are presented as means \pm S.D.

\begin{tabular}{|c|c|c|c|}
\hline Normal & Fibroadenoma & $\begin{array}{l}\text { Intraductal } \\
\text { carcinoma }\end{array}$ & $\begin{array}{l}\text { Invasive ductal } \\
\text { carcinoma }\end{array}$ \\
\hline $\begin{array}{l}69 \cdot 0 \pm 21 \cdot 5 \\
(n=3)\end{array}$ & $\begin{array}{l}99 \cdot 5 \pm 12 \cdot 5 \\
(n=3)\end{array}$ & $\begin{array}{l}195 \cdot 5 \pm 33 \cdot 5 \\
(n=3)\end{array}$ & $\begin{array}{l}102 \cdot 0 \pm 13 \\
(n=3)\end{array}$ \\
\hline
\end{tabular}

prepared whole lysates of fresh frozen biopsies and hGH protein content was analyzed by ELISA. All samples examined demonstrated the presence of hGH protein. The mean hGH concentrations in the examined samples are presented in Table 1. We observed the presence of hGH protein in tissue lysates derived from normal mammary gland and increased levels of hGH protein in the three proliferative disorders of the mammary gland. We have also confirmed the secretion of hGH protein in primary mammary epithelial culture (data not shown).

\section{Cellular localization of $h \mathrm{GH}$ gene expression in axillary lymph node metastasis of mammary carcinoma by in situ RT-PCR and ISH}

Axillary lymph nodes removed from patients with carcinoma of the mammary gland were examined for the presence of hGH gene expression. We localized and compared hGH gene expression between axillary lymph nodes containing and not containing metastatic mammary carcinoma cells. The structural characteristic of the invaded lymph nodes is that the metastatic carcinoma cells filled and extended into the subcapsular and radial sinuses of the lymph node before stromal invasion, recapitulating

\footnotetext{
Figure 2 Demonstration of hGH gene expression in proliferative mammary gland disorders by RT-PCR (A) and by in situ RT-PCR (B-I). (A) Lane 1, 342 bp hGH amplified fragment from fibroadenoma; lane 2, Rsal digest of lane 1; lane 3, amplified $\beta$-actin fragment from fibroadenoma; lane 4, amplified hGH fragment from in situ carcinoma; lane 5, Rsal digest of lane 4; lane 6, 582 bp amplified $\beta$-actin fragment from in situ carcinoma; lane 7, lack of amplified fragment from fibroadenoma when Taq DNA polymerase was omitted; lane 8, amplified hGH fragment from invasive ductal carcinoma; lane 9, Rsal digest of lane 8; lane 10, amplified $\beta$-actin fragment from invasive ductal carcinoma. (B) Section obtained from a patient with fibroadenoma; a very intense signal for hGH gene expression was observed in proliferative epithelial cells and within the numerous fibroblasts (arrows) responsible for the neosynthesis of the loose stroma (asterisk). (C) No signal for hGH gene expression was detected on a consecutive section of fibroadenoma by direct ISH. (D) On a section obtained from a patient with in situ carcinoma of non-high-grade cribriform type, hGH mRNA was readily localized in the proliferative tumor cells, in myoepithelial cells which continuously circumscribed the ducts (arrows) and in lymphocytes of the inflammatory infiltrate. (E) On a section obtained from a patient with in situ carcinoma of high-grade type showing a typical myoepithelial cell lining disruption, the signal for hGH gene expression was abundant in the tumor cells, and particularly intense in myoepithelial cells (arrows) and in lymphocytes of the inflammatory infiltrate. (F) In situ RT-PCR performed without Taq DNA polymerase on an adjacent section obtained from a patient with in situ carcinoma. The faint signal observed on the lymphocytes corresponded to hybridization of the hGH cDNA obtained following the reverse transcription step. All the tumoral cells remained clearly negative. (G) On a section obtained from a patient with invasive ductal carcinoma a very intense signal for hGH mRNA was localized in the strands of tumoral cells extending into the loose fibrillar stroma. Fibroblastic cells also exhibited a strong signal for hGH gene expression (arrows). (H) Lack of signal for hGH gene expression when the reverse transcription step was omitted on an adjacent section of invasive ductal carcinoma. (I) On a section obtained from a patient with invasive ductal carcinoma, the signal for hGH gene expression was also abundantly distributed at the margin of the advancing carcinoma characterized by important angiogenesis. The hGH gene was expressed in all neoplastic cells, fibroblasts of the accompanying peritumoral stroma (arrows), endothelial cells (arrowheads), smooth muscle cells of the tunica media (open arrow) and circulating lymphocytes (open arrowhead), whereas erythrocytes remained negative. Bar is $100 \mu \mathrm{m}$.
} 

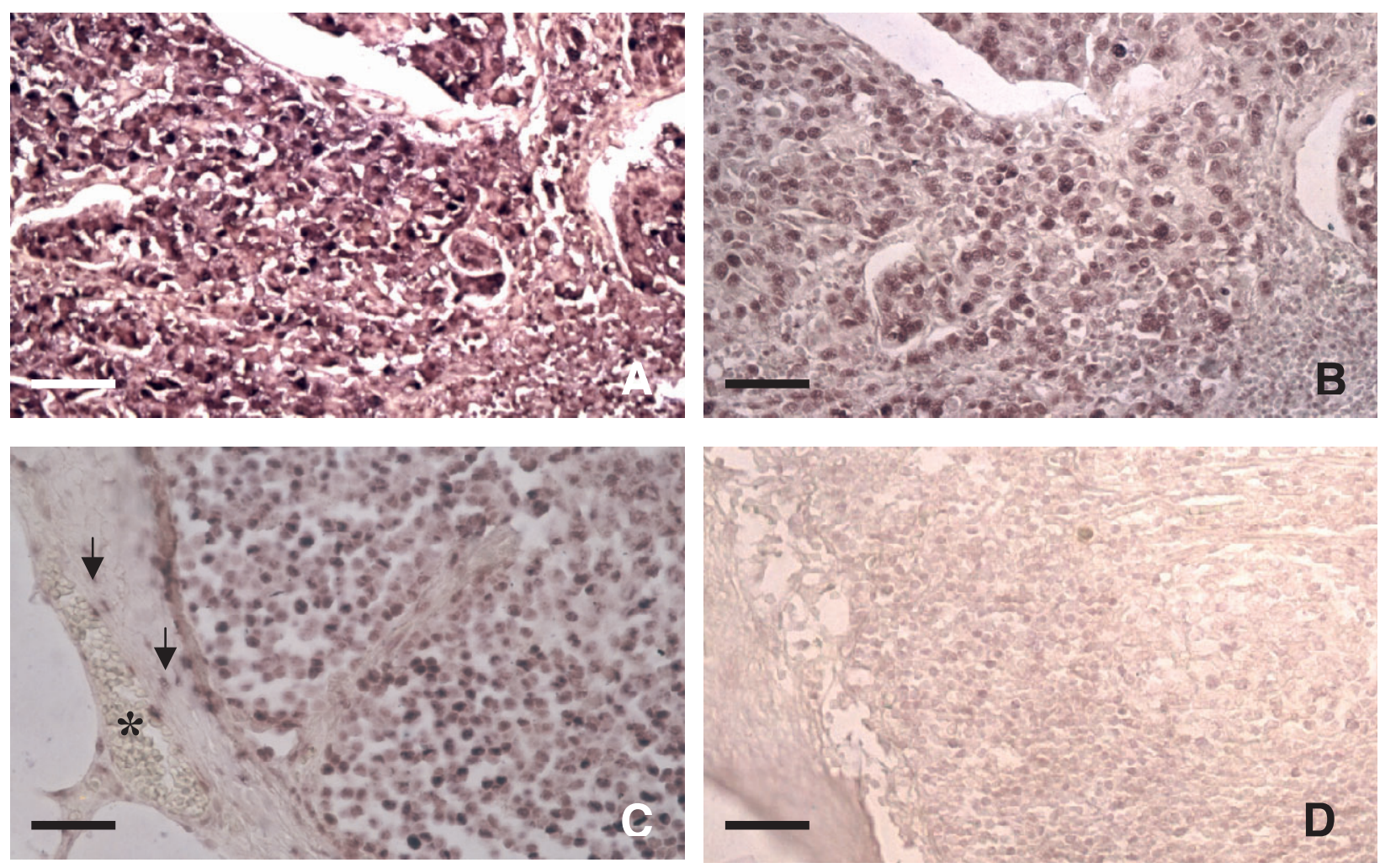

Figure 3 Cellular localization of hGH gene expression by in situ RT-PCR (A, C) and ISH (B, D) in axillary lymph nodes containing (A, B) and not containing $(C, D)$ metastatic mammary carcinoma. (A) On a section of lymph node containing metastatic mammary carcinoma, an intense signal for hGH mRNA was associated with the metastatic carcinoma cells and with the residual lymphoid components. (B) ISH for hGH gene expression on an adjacent section of a lymph node containing metastatic mammary carcinoma demonstrates that the signal for hGH mRNA is associated with the same cell types (metastatic mammary carcinoma cells and lymphocytes) albeit with lesser intensity compared with the signal obtained after in situ RT-PCR (B vs A). (C) On a section of axillary lymph nodes not containing metastatic mammary carcinoma, hGH gene expression was clearly localized by in situ RT-PCR in the B-cell follicle of the cortex and in fibroblastic component (arrows) of the connective tissue of the capsule and radial sinus, while dendritic reticular cells remained negative. Endothelial cells of post-capillary venules (asterisk) also synthesized hGH mRNA. (D) No signal for hGH gene expression could be detected by ISH on an adjacent section of the axillary lymph node not containing metastatic mammary carcinoma. Bar is $100 \mu \mathrm{m}$.

the architectural patterns and cellular features of the primary carcinoma. In lymph nodes containing mammary metastatic cells hGH gene expression could be readily detected by in situ RT-PCR both in the cohesive strands of mammary carcinoma cells and in the residual lymphoid tissue (Fig. 3A). Interestingly, we were also able to detect hGH gene expression in the metastatic mammary carcinoma cells and in stromal lymphocytes by simply performing ISH (Fig. 3B). In the lymph nodes not containing metastatic mammary carcinoma cells hGH mRNA was readily detected by use of the in situ RT-PCR methodology (Fig. 3C). Cellular hGH gene expression was particularly abundant in the B-cell follicle of the cortex while the dendritic reticular cells did not express the hGH gene (Fig. 3C). The presence of hGH mRNA was also detected in fibroblasts of the fibrous connective tissue capsule and in endothelial cells of the post-capillary venules (Fig. 3C). In contrast to the invaded lymph node, hGH gene expression could not be evidenced by simply performing ISH on sections of non-invaded lymph nodes (Fig. 3D). Thus, based on the differential sensitivities of in situ RT-PCR and ISH, metastatic mammary carcinoma cells express higher levels of hGH mRNA than epithelial cells of the normal mammary gland and the neoplastic cells of both intraductal and invasive ductal carcinoma of the human mammary gland.

\section{Discussion}

We have demonstrated here that hGH mRNA is expressed, albeit in low copy number, primarily in the ductal epithelial cells of the normal human mammary gland. We identified the cell types expressing hGH mRNA by use of the in situ RT-PCR technique designed for cellular localization of low copy number mRNAs within a complex tissue and with optimal morphological preservation (Morel et al. 1998, Recher et al. 2001). 
This detection method overcomes technical limitations of Northern blotting, and is more sensitive than liquid PCR when performed under the same conditions (Bates et al. 1997). The oligonucleotide primers used were designed in order to prevent diffusion of the PCR product, as previously characterized (Recher et al. 2001), and generated a PCR product of $342 \mathrm{bp}$ identical to the product obtained from MCF-7 cells transfected with the hGH gene (Kaulsay et al. 1999). Our results presented here are in agreement with a previous study in which hGH mRNA was detected in RNA samples isolated from normal human mammary gland by RT-PCR (Mol et al. 1995a). However, this study did not localize the cellular expression of hGH mRNA and therefore the hGH mRNA detected by RT-PCR may have been provided by cells not of mammary origin, such as lymphocytes infiltrating the mammary stroma. Other studies have reported (Hattori et al. 1990, Wu et al. 1996) and we have also demonstrated here that human lymphocytes express abundant hGH mRNA. In support of our demonstration of hGH mRNA in epithelial cells of the human mammary gland, GH gene expression has previously been localized to the epithelial components of normal canine and feline mammary glands (Mol et al. 1995b, van Garderen et al. 1995). hGH protein has been detected by immunocytochemistry on frozen sections of normal human mammary gland in mammary epithelial cells (Mol et al. 1995a) although with this technique it is impossible to state whether it is of endocrine or autocrine origin. We are also able to detect $\mathrm{hGH}$ protein from frozen samples of normal human mammary gland (this study) and also by primary human mammary epithelial cells in culture (data not shown). Thus, the epithelial cell component of the human mammary gland is one location for extrapituitary expression of hGH.

We also demonstrate here that hGH mRNA is expressed in at least three proliferative pathologies of the human mammary gland, namely fibroadenoma, intraductal carcinoma and invasive ductal carcinoma. We have also previously demonstrated the expression of the hGH receptor primarily in the epithelial cells of the same proliferative disorders (Mertani et al. 1998). Quantification of the cellular hGH receptor mRNA in these pathologies did not reveal differential expression of hGH receptor mRNA (Emerman et al. 1985). Although in situ RT-PCR is not a quantitative technique, we consistently observed a more prominent signal for hGH mRNA in the neoplastic epithelial cells in each of the three examined pathologies in comparison with epithelial cells in the surrounding normal mammary tissue. We therefore hypothesized that locally produced hGH, per se, or increases in the local concentration of hGH may alter the proliferative behavior of mammary epithelial cells. We verified this assumption by the demonstration of increased hGH per milligram protein in extracts derived from the three studied proliferative disorders of the mammary gland when compared with normal mammary gland. We have recently established a model system to study the role of autocrine-produced hGH in mammary carcinoma by stable transfection of the $\mathrm{hGH}$ gene or a translation-deficient gene into MCF-7 cells (designated MCF-hGH and MCF-MUT respectively). Indeed, we observed a marked increase in MCF-hGH cell number in both serum-free and serumcontaining media in comparison with MCF-MUT cells (Kaulsay et al. 1999). Interestingly the increase in cell number observed in the MCF-hGH cell line is achieved with extremely low concentrations of hGH of around $100 \mathrm{pM}$ under the experimental conditions utilized (Kaulsay et al. 1999). This is in contrast to $50-100 \mathrm{nM}$ exogenously added hGH required to achieve the maximal increase in MCF-MUT cell number possible with exogenous hGH, still comparatively less than that obtained with autocrine hGH (Kaulsay et al. 1999). It should be noted that the concentration of hGH protein determined in the pathological samples examined here approximates that of our model system. Thus, smaller amounts of autocrine hGH (in comparison with exogenous hGH) are required to produce an increase in cell number and this may provide an explanation for the low copy number of hGH mRNA expressed in mammary epithelial cells and pathologies thereof. The increase in mammary carcinoma cell number stimulated by hGH is a result of both increased mitogenesis and decreased apoptosis (Kaulsay et al. 2001). The decreased apoptosis observed in MCFhGH cells in comparison with MCF-MUT cells may account for the increased molar potency of autocrine hGH to stimulate increases in mammary carcinoma cell number, as exogenous hGH poorly inhibited mammary carcinoma apoptotic cell death (Kaulsay et al. 2001). By use of cDNA array technology we have now identified several genes that are preferentially regulated by the autocrine production of hGH in mammary carcinoma cells (Mertani et al. 2001). For example, autocrine hGH but not exogenous hGH stimulation of mammary carcinoma cells results in a transcriptional-dependent increase in CHOP, which offers protection from apoptosis in a p38 MAP kinasedependent manner (Mertani et al. 2001). Furthermore, autocrine $\mathrm{hGH}$ but not exogenous $\mathrm{hGH}$ results in a transcriptional downregulation of the PTGF- $\beta$ gene and product in mammary carcinoma cells, with the resultant loss of PTGF- $\beta$-stimulated apoptotic cell death (Graichen et al. 2002). Thus, hGH translated from the human mammary epithelial cell will increase cell number in proliferative disorders of the mammary gland.

We have also demonstrated here that the cells of the stromal compartment in proliferative disorders of the mammary gland gain the ability to express hGH mRNA. Presumably, factors secreted from the hyperproliferating mammary epithelial cells or stromal cell contacts result in the de novo expression of the hGH gene. In this regard it is interesting that GH-releasing hormone (GHRH) (Kahan et al. 2000) and its receptor (Rekasi et al. 2000) 
are expressed by mammary epithelial cells and GHRH antagonists inhibit the proliferation of mammary carcinoma cells in vivo (Kahan et al. 2000) and in vitro (Rekasi et al. 2000). Paracrine GHRH released by mammary epithelial cells may therefore stimulate fibroblastic hGH gene expression if the GHRH receptor is expressed on mammary fibroblasts. The functional role, in particular in the regulation of normal tissue boundaries, of the fibroblastic expression of $\mathrm{hGH}$ in proliferative disorders of the human mammary gland remains to be determined. The autocrine/paracrine production of other $\mathrm{GH}$-dependent growth factors by mammary stromal cells has been demonstrated to play an essential role in mammary epithelial cell proliferation and differentiation during carcinogenesis both in vivo and in vitro (Cullen \& Lippman 1992, Shekhar et al. 2001). For example, it has been demonstrated that enhanced expression of IGF-I and its receptor in mammary stromal cells is associated with exaggerated reactive stroma formation (Cullen et al. 1990, Yee et al. 1989). Indeed, several observations support the concept that deregulation of epithelial-mesenchymal interactions is linked to cellular proliferation and tumor formation (reviewed in Park et al. 2000). It is therefore worthy of note that neoplastic progression of MCF-7 cells transplanted into the fat pad of GH-deficient lit/lit mice is significantly reduced in comparison with control hosts (Yang et al. 1996). Although GH effects on the stromal microenvironment have been functionally defined in experimental animals (Feldman et al. 1993, Gallego et al. 2001), its contribution to neoplastic progression of the human mammary gland has yet to be determined. The prominent expression of the hGH gene observed in vascular components of the mammary neoplasm also suggests an important role for autocrine/paracrine hGH in angiogenesis required for tumor support and dissemination. We have previously demonstrated endothelial and smooth muscle cell expression of the hGH receptor in vascular components of the normal and neoplastic human mammary gland (Mertani et al. 1998), which would permit locally produced hGH to act in an autocrine/ paracrine manner. It is therefore interesting to note that hGH has previously been demonstrated to potently stimulate angiogenesis in different experimental models (Gould et al. 1995, Smith et al. 1997, Struman et al. 1999). Activation of local host stroma by autocrine hGH production is suggested by our observations reported here showing that $\mathrm{hGH}$ gene expression is particularly abundant between transition periods from normal mammary gland to fibroadenoma and from ductal to invasive carcinoma. Studies utilizing a nude mouse model injected with mammary carcinoma cells not producing or producing autocrine hGH may be useful to delineate the angiogenic potential of hGH in mammary carcinoma.

Interestingly, we have demonstrated here that metastatic mammary carcinoma cells express higher levels of hGH mRNA than neoplastic cells of both intraductal carcinoma and invasive ductal carcinoma. This was primarily evidenced by the ability to detect hGH mRNA in metastatic mammary carcinoma cells by simple ISH in comparison with non-metastatic neoplastic mammary epithelial cells where hGH mRNA was only detected by in situ RT-PCR. We are also able to detect strong expression of the $\mathrm{GH}$ receptor gene and protein (M Raccurt, E Moudilou, G Morel \& H C Mertani, unpublished observations) suggestive of an autocrine/ paracrine mechanism of $\mathrm{GH}$ action during metastatic spreading. We have previously demonstrated that autocrine production of hGH by mammary carcinoma cells cultured on a collagen substrate dramatically alters their morphology to one reminiscent of that observed in epithelio-mesenchymal transition, and also strongly enhances their ability to spread on a collagen matrix (Kaulsay et al. 2000). Autocrine production of hGH by mammary carcinoma cells could therefore be expected to regulate mammary carcinoma cell migration and/or invasion. In this regard, it is interesting that we have observed that autocrine production of hGH by mammary carcinoma cells results in increased $\beta$-catenin mRNA (Mertani et al. 2001). We have also recently observed that autocrine production of hGH results in increased nuclear $\beta$-catenin and transactivation of a T-cell factor-responsive promoter in the presence of inhibitors of glycogen synthase kinase $3 \beta$ (S Mukhina, HC Mertani \& P E Lobie, unpublished observations). The expression of $\beta$-catenin has been reported to be increased in invasive carcinoma of the mammary gland (Karayiannakis et al. 2001). Furthermore we have also identified clusterin and the serine/ threonine kinase activin type 1 receptor as two further genes upregulated by autocrine hGH (Mertani et al. 2001). Clusterin has recently been demonstrated to induce the formation of vascular smooth muscle cell nodules and to facilitate their migration (Millis et al. 2001), and activin A is directly involved in remodeling of the mammary microecology in the tumor-host invasion field (Ohga et al. 1996). By use of differential display we have also identified reticulocalbin, whose expression has been demonstrated to be higher in metastatic mammary carcinoma cells (Liu et al. 1997), to be upregulated by autocrine production of hGH in mammary carcinoma cells (H C Mertani, E L Goh \& P E Lobie, unpublished observations). It is therefore plausible to expect that autocrine production of hGH by mammary carcinoma cells may promote their dissemination in vivo. Interestingly though, exogenous hGH has actually been demonstrated to inhibit the pulmonary metastasis of prostate cancer in tumor-bearing animals (Torosian \& Donoway 1991, Torosian 1993). It is likely that hGH may exert cell-type-specific effects on cell motility or metastatic behavior. In addition the metastatic potential of a tumor is positively correlated with size (Makhlouf et al. 1999). In a prostate cancer model, hGH did not increase tumor size (Torosian \& Donoway 1991, Torosian 1993) whereas we have reported that autocrine 
production of hGH stimulates the hyperproliferation of mammary carcinoma cells and hGH exposure could therefore be expected to result in increased tumor volume in vivo. Supporting this hypothesis, it has been reported that exogenously administered hGH results in an increase in mammary glandular size in primates $(\mathrm{Ng}$ et al. 1997). Further studies are now required to evaluate the precise contribution of autocrine/paracrine hGH on cell-matrix interactions and the invasive behavior of mammary carcinoma cells, with particular focus on alteration in expression or functions of cellular adhesion and metastasis-related molecules. In particular, since the GH response is known to depend on the target cell and the context in which the stimulation occurs, elucidation of genes activated by autocrine $\mathrm{GH}$ production within the reactive stroma would identify the basis of the onset and progression of GHdependent carcinoma of the mammary gland.

In conclusion, we have demonstrated that the hGH gene is expressed primarily in epithelial cells of the normal human mammary gland and that proliferative disorders of the mammary gland are associated with concomitant stromal hGH gene expression. Further, it is apparent that increased expression of the hGH gene is associated with metastatic mammary carcinoma cells. It is now necessary to delineate the pathophysiological role of hGH in the neoplastic progression of the mammary gland. Should autocrine $\mathrm{hGH}$ production by mammary carcinoma cells be demonstrated to alter the clinical prognosis of carcinoma of the mammary gland then use of specific GH antagonistic adjunct therapy should be considered. Indeed, we have already demonstrated (Kaulsay et al. 2001) that the $\mathrm{hGH}$ receptor antagonist $\mathrm{B} 2036$ is able to inhibit the proliferative, anti-apoptotic, transcriptional and morphological effects of autocrine hGH production in mammary cells.

\section{Acknowledgements}

The authors thank R Dante, A Géloën and J M Péquignot for helpful discussions. This work was supported by a grant from La ligue Contre le Cancer, Fédération Savoie to G M.

\section{References}

Bates PJ, Sanderson G, Holgate ST \& Johnston SL 1997 A comparison of RT-PCR, in-situ hybridisation and in-situ RT-PCR for the detection of rhinovirus infection in paraffin section. Journal of Virological Methods 67 153-160.

Cullen KJ \& Lippman ME 1992 Stromal-epithelial interactions in breast cancer. Cancer Treatment Research 61 413-431.

Cullen KJ, Yee D, Sly WS, Perdue J, Hampton B, Lippman ME \& Rosen N 1990 Insulin-like growth factor receptor expression and function in human breast cancer. Cancer Research 50 48-53.

Decouvelaere C, Peyrat JP, Bonneterre J, Djiane J \& Jammes H 1995 Presence of the two growth hormone receptor messenger RNA isoforms in human breast cancer. Cell Growth and Differentiation 6 $477-483$.
Emerman JT, Leahy M, Gout PW \& Bruchovsky N 1985 Elevated growth hormone levels in sera from breast cancer patients. Hormone and Metabolism Research 17 421-424.

Feldman M, Ruan W, Cunningham BC, Wells JA \& Kleinberg DL 1993 Evidence that the growth hormone receptor mediates differentiation and development of the mammary gland. Endocrinology 133 1602-1608.

Gallego MI, Binart N, Robinson GW, Okagaki R, Coschigano KT, Perry J, Kopchick JJ, Oka T, Kelly PA \& Hennighausen L 2001 Prolactin, growth hormone, and epidermal growth factor activate Stat5 in different compartments of mammary tissue and exert different and overlapping developmental effects. Developmental Biology 229 163-175.

van Garderen E, de Wit M, Voorhout WF, Rutteman GR, Mol JA, Nederbragt H \& Misdorp W 1997 Expression of growth hormone in canine mammary tissue and mammary tumors. Evidence for a potential autocrine/paracrine stimulatory loop. American Journal of Pathology 150 1037-1047.

Gebre-Medhin M, Kindblom LG, Wennbo H, Törnell J \& Meis-Kindblom JM 2001 Growth hormone receptor is expressed in human breast cancer. American Journal of Pathology 158 1217-1222.

Gould J, Aramburo C, Capdevielle M \& Scanes CG 1995 Angiogenic activity of anterior pituitary tissue and growth hormone on the chick embryo chorio-allantoic membrane: a novel action of GH. Life Sciences 56 587-594.

Graichen R, Liu D, Sun Y, Lee KO \& Lobie PE 2002 Autocrine human growth hormone inhibits placental transforming growth factor-beta gene transcription to prevent apoptosis and allow cell cycle progression of human mammary carcinoma cells. Journal of Biological Chemistry 277 26662-26672.

Hankinson SE, Willett WC, Colditz GA, Hunter DJ, Michaud DS, Deroo B, Rosner B, Speizer FE \& Pollak M 1998 Circulating concentrations of insulin-like growth factor-I and risk of breast cancer. Lancet 351 1393-1396.

Hattori N, Shimatsu A, Sugita M, Kumagai S \& Imura H 1990 Immunoreactive growth hormone $(\mathrm{GH})$ secretion by human lymphocytes: augmented release by exogenous GH. Biochemical and Biophysical Research Communications 168 396-401.

Kahan Z, Varga JL, Schally AV, Rekasi Z, Armatis P, Chatzistamou L, Czompoly T \& Halmos G 2000 Antagonists of growth hormone-releasing hormone arrest the growth of MDA-MB-468 estrogen-independent human breast cancers in nude mice. Breast Cancer Research and Treatment 60 71-79.

Karayiannakis AJ, Nakopoulou L, Gakiopoulou H, Keramopoulos A, Davaris PS \& Pignatelli M 2001 Expression patterns of beta-catenin in in situ and invasive breast cancer. European Journal of Surgical Oncology 27 31-36.

Kaulsay KK, Mertani HC, Tornell J, Morel G, Lee KO \& Lobie PE 1999 Autocrine stimulation of human mammary carcinoma cell proliferation by human growth hormone. Experimental Cell Research $25035-50$.

Kaulsay KK, Mertani HC, Lee KO \& Lobie PE 2000 Autocrine human growth hormone enhancement of human mammary carcinoma cell spreading is Jak2 dependent. Endocrinology 141 1571-1584.

Kaulsay KK, Zhu T, Bennett W, Lee K \& Lobie PE 2001 The effects of autocrine human growth hormone (hGH) on human mammary carcinoma cell behavior are mediated via the hGH receptor. Endocrinology 142 767-777.

Liu Z, Brattain MG \& Appert H 1997 Differential display of reticulocalbin in the highly invasive cell line, MDA-MB-435, versus the poorly invasive cell line, MCF-7. Biochemical and Biophysical Research Communications 231 283-289.

Maddox PR, Jones DL \& Mansel RE 1992 Prolactin and total lactogenic hormone measured by microbioassay and immunoassay in breast cancer. British Journal of Cancer 65 456-460. 
Makhlouf HR, Burke AP \& Sobin LH 1999 Carcinoid tumors of the ampulla of Vater: a comparison with duodenal carcinoid tumors. Cancer 85 1241-1249.

Mertani HC, Delehaye-Zervas MC, Martini JF, Postel-Vinay MC \& Morel G 1995 Localization of growth hormone receptor messenger RNA in human tissues. Endocrine 3 135-142.

Mertani HC, Garcia-Caballero T, Lambert A, Gerard F, Palayer C, Boutin JM, Vonderhaar BK, Waters MJ, Lobie PE \& Morel G 1998 Cellular expression of growth hormone and prolactin receptors in human breast disorders. International Journal of Cancer $\mathbf{7 9}$ 202-211.

Mertani HC, Zhu T, Goh ELK, Lee KO, Morel G \& Lobie PE 2001 Autocrine human growth hormone $(\mathrm{hGH})$ regulation of human mammary carcinoma cell gene expression. Identification of $\mathrm{CHOP}$ as a mediator of hGH stimulated human mammary carcinoma cell survival. Journal of Biological Chemistry 276 21464-21475.

Millis AJ, Luciani M, McCue HM, Rosenberg ME \& Moulson CL 2001 Clusterin regulates vascular smooth muscle cell nodule formation and migration. Journal of Cell Physiology 186 210-219.

Mol JA, Henzen-Logmans SC, Hageman P, Misdorp W, Blankenstein MA \& Rijnberk A 1995a Expression of the gene encoding growth hormone in the human mammary gland. Journal of Clinical Endocrinology and Metabolism 80 3094-3096.

Mol JA, van Garderen E, Selman PJ, Wolfswinkel J, Rijinberk A \& Rutteman GR $1995 b$ Growth hormone mRNA in mammary gland tumors of dogs and cats. Journal of Clinical Investigation 95 2028-2034.

Morel G, Berger M, Ronsin B, Recher S, Ricard-Blum S, Mertani HC \& Lobie PE 1998 In situ reverse transcription-polymerase chain reaction. Applications for light and electron microscopy. Biology of the Cell 90 137-154.

Ng ST, Zhou J, Adesanya OO, Wang J, LeRoith D \& Bondy CA 1997 Growth hormone treatment induces mammary gland hyperplasia in aging primates. Nature Medicine 3 1141-1144.

Ohga E, Matsuse T, Teramoto S, Katayama H, Nagase T, Fukuchi Y \& Ouchi Y 1996 Effects of activin A on proliferation and differentiation of human lung fibroblasts. Biochemical and Biophysical Research Communications 228 391-396.

Park CC, Bissell MJ \& Barcellos-Hoff MH 2000 The influence of the microenvironment on the malignant phenotype. Molecular Medicine Today 6 324-329.

Peyrat JP, Bonneterre J, Hecquet B, Vennin P, Louchez MM, Fournier C, Lefebvre J \& Demaille A 1993 Plasma insulin-like growth factor-I (IGF-I) concentrations in human breast cancer. European Journal of Cancer 29 492-497.

Recher S, Raccurt M, Lambert A, Lobie PE, Mertani HC \& Morel G 2001 Prenatal and adult growth hormone gene expression in rat lymphoid organs. Journal of Histochemistry and Cytochemistry 49 347-354.
Rekasi Z, Czompoly T, Schally AV \& Halmos G 2000 Isolation and sequencing of cDNAs for splice variants of growth hormone-releasing hormone receptors from human cancers. PNAS 97 10561-10566.

Rose DP, Berke B \& Cohen LA 1988 Serum prolactin and growth hormone determined by radioimmunoassay and a two-site immunoradiometric assay: comparison with the $\mathrm{Nb} 2$ cell bioassay. Hormone and Metabolism Research 20 49-53.

Shekhar MP, Werdell J, Santner SJ, Pauley RJ \& Tait L 2001 Breast stroma plays a dominant regulatory role in breast epithelial growth and differentiation: implications for tumor development and progression. Cancer Research 61 1320-1326.

Smith LE, Kopchick JJ, Chen W, Knapp J, Kinose F, Daley D, Foley E, Smith RG \& Schaeffer JM 1997 Essential role of growth hormone in ischemia-induced retinal neovascularization. Science $\mathbf{2 7 6}$ 1706-1709.

Sobrier ML, Duquesnoy P, Duriez B, Amselem S \& Goossens M 1993 Expression and binding properties of two isoforms of the human growth hormone receptor. FEBS Letters 319 16-20.

Struman I, Bentzien F, Lee H, Mainfroid V, D'Angelo G, Goffin V, Weiner RI \& Martial JA 1999 Opposing actions of intact and $\mathrm{N}$-terminal fragments of the human prolactin/growth hormone family members on angiogenesis: an efficient mechanism for the regulation of angiogenesis. PNAS 96 1246-1251.

Toniolo P, Bruning PF, Akhmedkhanov A, Bonfrer JM, Koenig KL, Lukanova A, Shore RE \& Zeleniuch-Jacquotte A 2000 Serum insulin-like growth factor-I and breast cancer. International Journal of Cancer 88 828-832.

Torosian MH 1993 Growth hormone and prostate cancer growth and metastasis in tumor-bearing animals. Journal of Pediatric Endocrinology 6 93-97.

Torosian MH \& Donoway RB 1991 Growth hormone inhibits tumor metastasis. Cancer 7 2280-228.

Wu H, Devi R \& Malarkey WB 1996 Localization of growth hormone messenger ribonucleic acid in the human immune system - a Clinical Research Center study. Journal of Clinical Endocrinology and Metabolism 81 1278-1282.

Yang XF, Beamer WG, Huynh H \& Pollak M 1996 Reduced growth of human breast cancer xenografts in hosts homozygous for the lit mutation. Cancer Research 56 1509-1511.

Yee D, Paik S, Lebovic GS, Marcus RR, Favoni RE, Cullen KJ, Lippman ME \& Rosen N 1989 Analysis of insulin-like growth factor I gene expression in malignancy: evidence for a paracrine role in human breast cancer. Molecular Endocrinology 3 509-517.

Received 22 April 2002

Accepted 2 July 2002 